\title{
Detailed Study of Perforated Beams with Closely Spaced Novel Web Openings
}

\author{
Konstantinos Daniel \\ TSAVDARIDIS \\ Academic Fellow \\ City University, London, \\ United Kingdom \\ ds016@city.ac.uk
}

K.D. Tsavdaridis, received his BEng and PhD degrees in Civil Engineering from City University and MSc (DIC) degrees in

Structural Engineering from Imperial College, London. His main research interests are in the areas of perforated steel beams conducting tests and FE analyses.
Cedric D'MELLO

Associate Dean

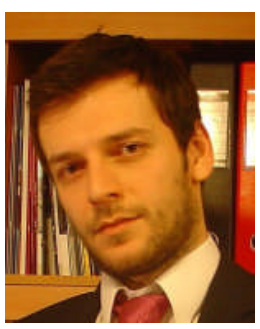

City University, London

United Kingdom

C.A.DMello@city.ac.uk

Cedric D'Mello, obtained his undergraduate and doctoral degrees in Structural Engineering from the University of Sussex. His main research interests are in the areas of composite structures and testing of large scale civil engineering structures.

\section{Summary}

This paper presents a detailed study of the behaviour of perforated steel beams with closely spaced web openings. Seven specimens including two typical cellular beams (i.e. circular web openings) and five perforated beams with novel web opening shapes were tested previously by the authors, to investigate the failure mode and load strength of the web-post between two adjacent web openings. These new novel web opening shapes improve the structural performance of the perforated beams with respect to web-post buckling failure. In addition, the manufacturing procedure of these novel web openings is improved and leads to sustainable design. The effects of web opening spacing/web opening depth of web-posts as well as the web opening depth/web thickness were studied to investigate the stability (slenderness) of the web-post subjected to vertical shear load. In comparison with the conventional cellular beams, significant advantages were obtained.

Keywords: Perforated steel beams; cellular beams; non-linear finite element analysis; web-post buckling; novel web opening shapes; web-post width; vertical shear capacity; parametric study; strut model; web-post stability

\section{Introduction}

The use of perforated steel beams has resulted in longer span floors. Their popularity has also increased because of an architectural emphasis on exposed structures, with cellular, castellated and elongated web openings being typical in structural steel sections. Sections having webs penetrated by large closely spaced openings over almost the full span are now common. Although the best application of these beams appears to be for long spans which are to carry a light uniform load, some heavy-mass structures, such as bridges, have been constructed using perforated beams for the full span. Also, with greater automation, the cost of their fabrication has been reduced to the level where for certain applications they may be competitive with open-web steel joists [1].

The last decade researchers examine standard web opening shapes (i.e. circular, rectangular and hexagonal) of perforated steel sections in order to provide a better understanding of the stress distribution in the vicinity of the web openings [2,3]. The current work presents a further investigation on perforated beams with closely spaced non-standard elliptically-based novel web opening shapes as first proposed by Tsavdaridis and D'Mello [4]. 
The main aim is to provide the maximum possible web opening area for the integration of services, such as hydraulics pipes, electric wires, ventilation systems, etc., whilst keeping the minimum possible self-weight. In addition, after separating and welding the top and bottom tee-sections, the higher the second moment of area the higher is the capacity of the perforated beams under bending. Hence, perforated beams with closely spaced novel web openings are necessary, without compromising the load carrying capacity of the web-post. This concept also leads to sustainable manufacturing and consequently construction and the following points were initially addressed for the design of the novel beams: i) design for minimum waste of material, ii) minimize energy is fabrication (i.e. oxy-cutting and welding) and in use and iii) aim for lean construction.

\section{Aim of the work}

The objective of this work was to examine the complex web-post buckling failure mode and the vertical shear capacity of web-post models. Initially, the FE model was validated against an experimental programme of work. The failure modes of perforated sections and the positions of high stress concentration points in the vicinity of the web openings were also considered. The aim was achieved by conducting an extensive FE parametric study on the web-posts using a buckling model that can be used for perforated sections with various closely spaced novel web opening shapes [4].

\section{Experimental program to validate the FE model}

\subsection{Introduction}

Experimental work was conducted on seven full scale steel perforated beams. Thereafter, the appropriate boundary conditions and input data were used in the FE study to simulate the local webpost failure for all of the web opening shapes.

\subsection{Specimen details}

The depth of the web openings should be low enough to prevent Vierendeel effects prior to webpost buckling failure in perforated sections with relatively thin webs. Hence, a diameter, $d_{o}$, equal to $0.7 h$ was used (Figure 1). The thickness of the stiffeners at supports is similar to the thickness of the flange (i.e. $t_{f}=10.9 \mathrm{~mm}$ ), while the thickness of the stiffeners at mid-span is $20 \mathrm{~mm}$ to allow for better stress distribution and avoid having stress concentration at the edges of the web openings close to the point load. Two different sets of tests were carried out as follows:

- A circular cellular beam (A1) and two cellular beams with fillets of $25 \mathrm{~mm}$ (A2) and 45mm (A3) introduced at the mid-depth of the web openings. With the advantage of profile cutting, the bigger the radius of the fillet, the larger is the depth of the final section and hence its second moment of area. (Table 1)

- A circular cellular beam (B1), two perforated sections with novel vertical elliptically-based web openings (B2 and B3) as well as one perforated section with novel inclined elliptically-based web openings (B4) symmetrically located to the mid-span. These web opening shapes consist of a combination of circular and straight lines (Table 1).

Four web opening shapes of the first category and another thirty-two shapes of the second category have been recently proposed and thoroughly examined for first time by Tsavdaridis [5]. It is worth noting that although the full advantages of developing those opening shapes are obtained using the profile manufacturing procedure, simple web cut-outs were considered for this research study in order to limit the number of geometric parameters. 


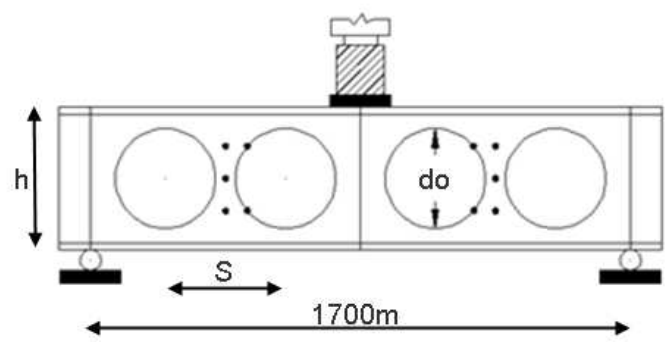

Cellular (UB457x152x52): $\mathrm{h}=449.8 \mathrm{~mm}, \mathrm{bf}=152.4 \mathrm{~mm}$, $\mathrm{t}_{\mathrm{f}}=10.9 \mathrm{~mm}, \mathrm{tw}_{\mathrm{w}}=7.6 \mathrm{~mm}, \mathrm{~d}_{0}=0.7 \mathrm{~h}=315 \mathrm{~mm}$, $\mathrm{S}=1.2 \mathrm{~d}_{0}=410.22 \mathrm{~mm}$, tmid-stiffener $=20 \mathrm{~mm}$

Element type: SHELL181

Element size: $15-20 \mathrm{~mm}$ (in total 3,445 elements)

Web: $f_{y}=375.3 \mathrm{MPa}, \mathrm{fu}_{\mathrm{u}}=492.7 \mathrm{MPa}$

Flange/Stiffner: $f_{y}=359.7 \mathrm{MPa}, f_{u}=480.9 \mathrm{MPa}$

$E=200 \mathrm{GPa}, \mathrm{v}=0.3$, Tang. Modulus $=2000 \mathrm{MPa}(=\mathrm{E} / 100)$

Fig. 1: Test arrangements, section properties and material properties

Table 1: The details of experimental tests

\begin{tabular}{ccccccc}
\hline Specimen & UB section & Open. Type & Specifications & $\begin{array}{c}\text { Web Open. } \\
\text { Spacing, } \boldsymbol{S}\end{array}$ & $\begin{array}{c}\text { Web-Post } \\
\text { Width }(\text { mm })\end{array}$ & $\begin{array}{c}\text { Opening } \\
\text { Area }\left(\mathbf{m m}^{2}\right)\end{array}$ \\
\hline A1 & $457 \times 152 \times 52$ & Circular & ---- & & 94,5 & 77931 \\
A2 & $457 \times 152 \times 52$ & Filleted Circular & $r=25 m m$ of fillets & $1,3 d_{o}$ & 48 & 78361 \\
A3 & $457 \times 152 \times 52$ & Filleted Circular & $r=45 m m$ of fillets & & 15 & 79129 \\
\hline B1 & $457 \times 152 \times 52$ & Circular & ---- & & 63 & 77931 \\
B2 & $457 \times 152 \times 52$ & Vertical Elliptical & THETA $=30$ and $R=0,3 d_{o}$ & $1,2 d_{o}$ & 63 & 56452 \\
B3 & $457 \times 152 \times 52$ & Vertical Elliptical & THETA $=10$ and $R=0,15 d_{o}$ & & 63 & 32138 \\
B4 & $457 \times 152 \times 52$ & Inclined Elliptical & THETA $=10$ and $R=0,25 d_{o}$ & & 63 & 45383 \\
\hline
\end{tabular}

\subsection{FE model description}

Analysis of the web-post using the finite element method (FEM) was based on ANSYS v11.0. SHELL181 plastic elements were used for this work, with an average maximum size of $20 \mathrm{~mm}$ in the vicinity of the web openings. The elasto-plastic material properties of the FE models were kept the same for all specimens. Young's Modulus and Poisson's Ratio equal to 200GPa and 0,3 were assigned, respectively. For the plastic properties of the steel material, two options were considered: i) the average values from coupon tests were used (FEM 1 in Figure 3) as well as ii) a nominal yield strength value $\left(f_{y}=355 \mathrm{MPa}\right)$ was used for comparison (FEM 2 in Figure 3 ). The Tangent Modulus value was assumed to be $580 \mathrm{MPa}$ for both options. Initial imperfections with maximum amplitude of $t_{w} / 200=7,6 / 200=0,038$ were also taken into account based on a previous study [5].

\subsection{Test procedure}

The test procedure followed was incrementally monotonic loading to failure, followed by full

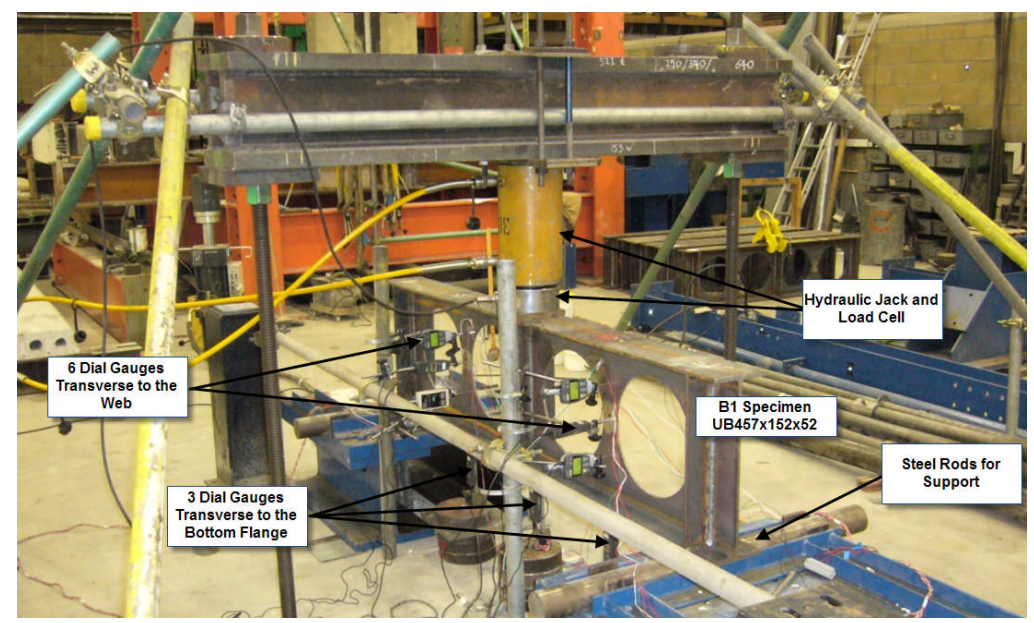
unloading. The post-elastic failure behaviour and the strain hardening were also examined. The apparatus for the testing program was arranged in such a way that a constant shear to moment interaction at each web-post was applied in all specimens. Data acquisition equipment was used to monitor the tests and alter the load increments for more precise results (Figure 2).

Fig. 2: Test set-up arrangement 


\subsection{Model verification}

An indicative graph of the load versus deformation curves subjected to buckling load is presented in Figure 3. Table 2 summarizes the test to FE ratios for the yielding load, buckling (or critical) load and ultimate loads as well as the failure modes of the tested specimens. This work led to the validation of the FE model, the use of the properties and assessment of the boundary conditions for the development of the local web-post FE model. Figure 4 shows the highly distorted web-posts for every specimen after failure together with schematic representation of Von-Mises stresses distribution. Some deviation of the results between critical buckling loads calculated using FEA and

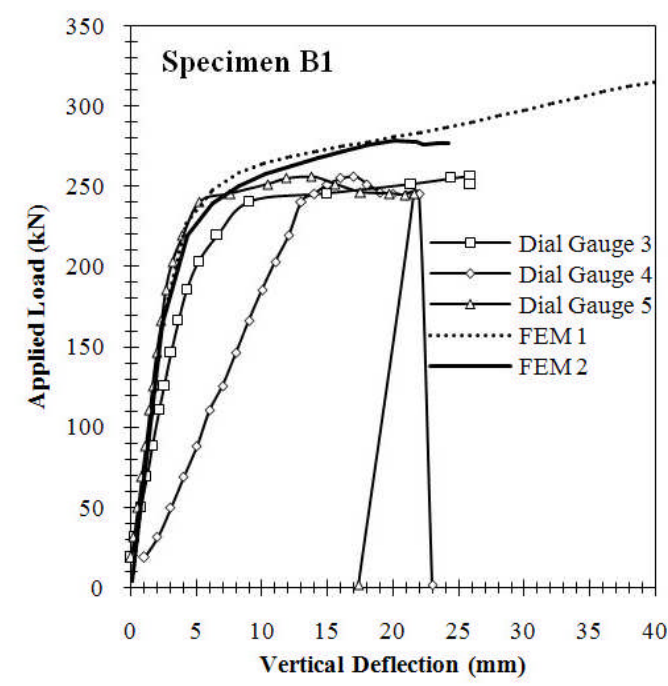
experimental buckling loads can be observed and is explained by the geometric imperfections caused by the manufacturing process. Even very small imperfections can cause a substantial fall in the buckling load.

In the first category it was easily seen that when beams with circular web openings with $45 \mathrm{~mm}$ of fillet were investigated, a very high stress concentration was observed at the notch point of the fillet. In the particular case, web-post rupture was obtained at a relatively low load level before any web-post buckling was observed. In the second category, the most important comparison is between Specimen B1 and B2 as the latter has almost 70\% of the cellular's web opening area, whilst its capacity is 1,6 times the capacity of B1.

Fig. 3: Comparison of experimental and FEM results

Table 2: Summary of experimental and FEM results

\begin{tabular}{|c|c|c|c|c|c|c|}
\hline \multirow{2}{*}{ Spec. } & at $P_{y}$ & at $P_{c r}$ & at $\boldsymbol{P}_{\text {ult. }}$ & \multirow{2}{*}{$\begin{array}{c}\text { Max. } \delta a t \\
P_{c r}(m m)\end{array}$} & \multirow{2}{*}{$\begin{array}{c}{ }^{a} \text { Primary Failure } \\
\text { Mode }\end{array}$} & \multirow{2}{*}{$\begin{array}{c}{ }^{b} \text { Strut-Tie } \\
\text { Angles } \\
\text { (degrees) }\end{array}$} \\
\hline & Test/FE & Test/FE & Test/FE & & & \\
\hline A1 & 0,94 & 0,82 & 0,84 & 5,69 & WPB & $132 /-44$ \\
\hline A2 & 0,90 & 0,99 & 0,92 & 7,09 & WPB & $129 /-44$ \\
\hline $\mathbf{A 3}$ & 0,89 & 0,58 & 0,51 & 8,54 & Mid-Post Rupture & --- \\
\hline B1 & 0,91 & 1,00 & 0,93 & 6,55 & WPB & $124 /-50$ \\
\hline B2 & 0,98 & 1,00 & 0,96 & 10,15 & WPB (1 side) & $135 /-43$ \\
\hline B3 & 0,98 & 1,20 & 0,97 & 6,92 & WPB (1 side) & $117 /-54$ \\
\hline B4 & 0,93 & 0,88 & 0,83 & 5,99 & WPB (1 side) & $127 /-46$ \\
\hline
\end{tabular}

${ }^{\mathrm{a}}$ WPB: Web-Post Buckling

${ }^{\mathrm{b}}$ Strut-Tie Angles to the Horizontal Mid-depth Web-post Centre-line (Top Tee/Bottom Tee)

\section{Parametric FE study}

\subsection{Introduction}

The FEA was carried out for a range of parameters such as web opening shape, spacing and web slenderness. It included material and geometrical non-linearity similar to the validated model above. The FE model used considered of a short section of beam between the centre-line of adjacent web openings. The ultimate strength of the web-post is governed by one of two modes: i) flexural failure caused by the development of a plastic hinge in the web-post, or ii) buckling failure of the web-post (double-sided web curvature). The mode of failure is dependent on the geometry of the web-post and hence the web opening shape. 


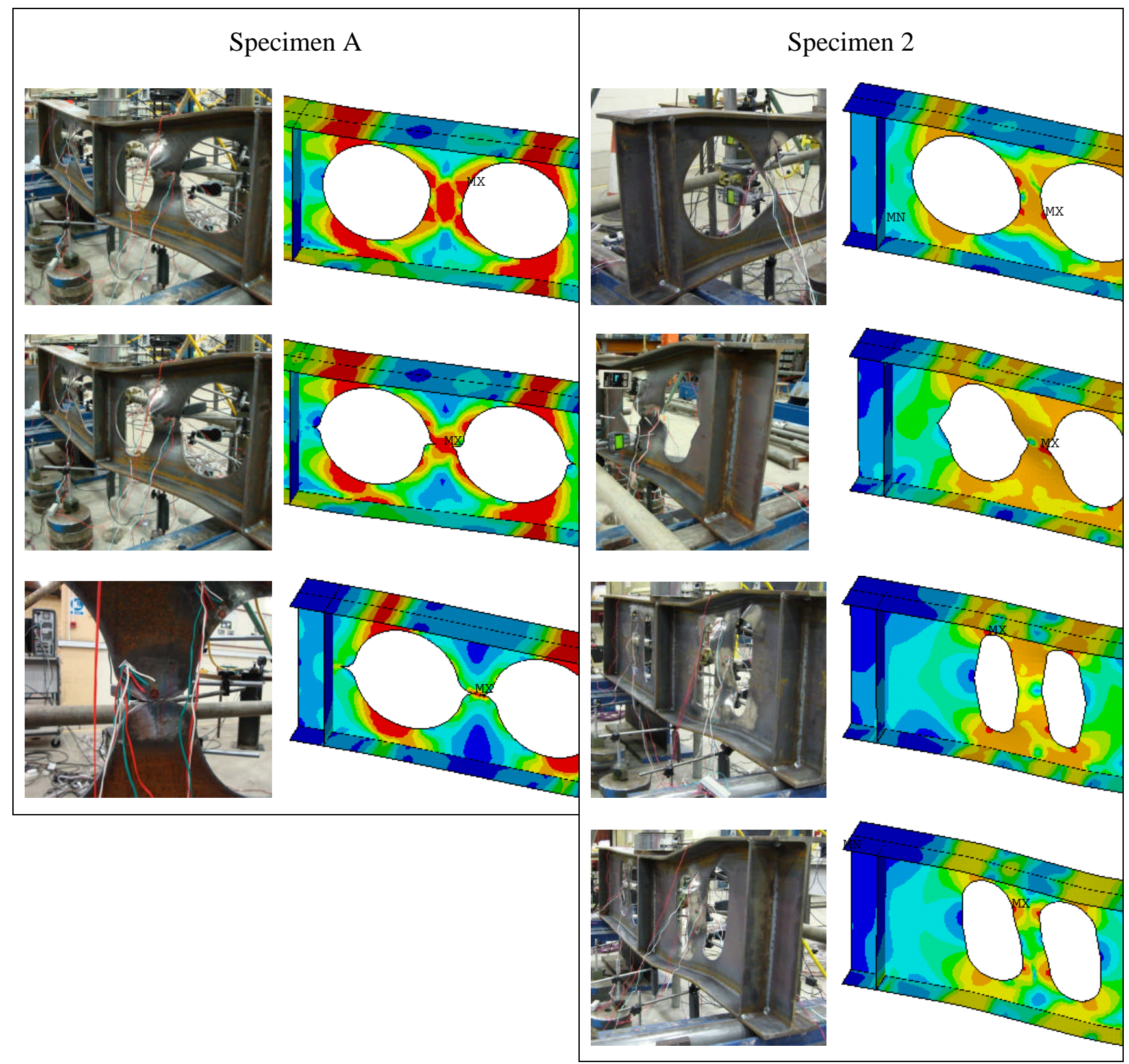

Fig. 4: Distorted web-posts after testing and Von-Mises stresses at failure

\subsection{FE models}

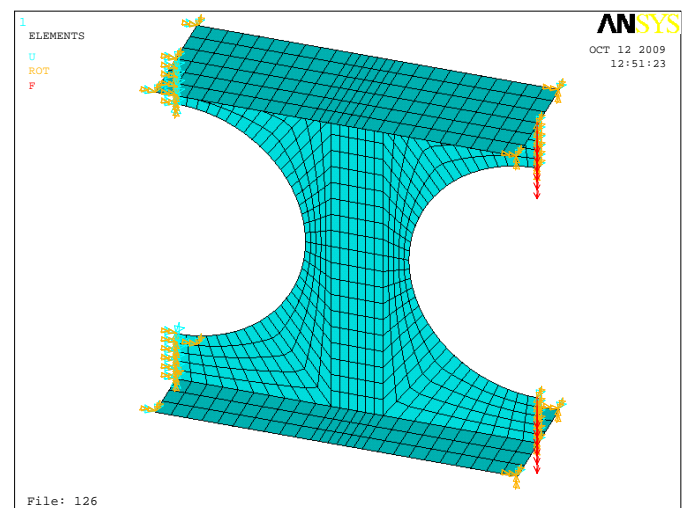

The FE model used in this study was based on the previous examined deep section. Only the aforementioned parameters were varied to be able to assess the effect on web-post capacity. Eight $S / d_{o}$ ratios were studied with five web thicknesses, giving $d_{o} / t_{w}$ ratios which varied from 30 to 80.8 . Table 3 summarises all the FE models examined with the corresponding characteristics.

Fig. 5: Boundary Conditions and Loading applied to the FE Model 
The boundary conditions used in the model are shown in Figure 5. The web-flange connection was assumed to be pinned as a safe lower bound, independent of the flange size and type of weld. In practice, some degree of fixity would exist, which increases the web buckling resistance.

The nominal material properties of steel grade S355 used as before. The material model used the Von-Mises yield criterion with kinematic hardening which is suitable for most metals, including steel.

Table 3: Number of every FE model with corresponding characteristics

Specimen A-1 \& B-1

\begin{tabular}{|c|c|c|c|c|c|c|}
\hline \multirow{2}{*}{$S$} & \multirow{2}{*}{$\begin{array}{l}\text { Width } \\
(\mathrm{mm})\end{array}$} & \multicolumn{5}{|c|}{ WEB THICKNESS, $t_{w}(\mathrm{~mm})$} \\
\hline & & 3,9 & 5 & 6 & 7,6 & 10,5 \\
\hline $1,1 d_{o}$ & 31.5 & 0,21 & 0,27 & 0,34 & 0,5 & 0,64 \\
\hline $1,2 d_{o}$ & 63 & 0,29 & 0,45 & 0,53 & 0,67 & 0,75 \\
\hline $1,3 d_{o}$ & 94,5 & 0,34 & 0,47 & 0,6 & 0,72 & 0,94 \\
\hline $1,4 d_{o}$ & 126 & 0,33 & 0,51 & 0,64 & 0,9 & 1,1 \\
\hline $1,5 d_{o}$ & 157,5 & 0,36 & 0,69 & 0,76 & 0,95 & 1,23 \\
\hline $1,6 d_{o}$ & 189 & 0,45 & 0,68 & 0,83 & 1,03 & 1,46 \\
\hline $1,7 d_{o}$ & 220,5 & 0,44 & 0,73 & 0,86 & 1,1 & 1,53 \\
\hline $1,8 d_{o}$ & 252 & 0,44 & 0,73 & 0,91 & 1,25 & 1,7 \\
\hline
\end{tabular}

Specimen A-2

\begin{tabular}{|c|c|c|c|c|c|c|}
\hline \multirow{2}{*}{$\boldsymbol{S}$} & \multirow{2}{*}{$\begin{array}{l}\text { Width } \\
\end{array}$} & \multicolumn{5}{|c|}{ WEB THICKNESS, $\boldsymbol{t}_{\boldsymbol{w}}(\mathbf{m m})$} \\
\cline { 3 - 7 } & $\mathbf{3 , 9}$ & $\mathbf{5}$ & $\mathbf{6}$ & $\mathbf{7 , 6}$ & $\mathbf{1 0 , 5}$ \\
\hline N.A. & N.A. & N.A. & N.A. & N.A. & N.A. & N.A. \\
\hline $\mathbf{1 , 2 d _ { \boldsymbol { o } }}$ & $\mathbf{6 3}$ & 0,346 & 0,524 & 0,632 & 0,852 & 0,879 \\
\hline $\mathbf{1 , 3 d _ { \boldsymbol { o } }}$ & $\mathbf{9 4 , 5}$ & 0,375 & 0,523 & 0,652 & 0,815 & 1,049 \\
\hline $\mathbf{1 , 4 d}_{\boldsymbol{o}}$ & $\mathbf{1 2 6}$ & 0,448 & 0,638 & 0,716 & 0,904 & 1,136 \\
\hline $\mathbf{1 , 5}_{\boldsymbol{o}}$ & $\mathbf{1 5 7 , 5}$ & 0,464 & 0,705 & 0,756 & 0,971 & 1,267 \\
\hline $\mathbf{1 , 6 d _ { \boldsymbol { o } }}$ & $\mathbf{1 8 9}$ & 0,473 & 0,723 & 0,829 & 1,029 & 1,399 \\
\hline $\mathbf{1 , 7 d _ { \boldsymbol { o } }}$ & $\mathbf{2 2 0 , 5}$ & 0,405 & 0,745 & 0,873 & 1,106 & 1,562 \\
\hline $\mathbf{1 , 8 d _ { \boldsymbol { o } }}$ & $\mathbf{2 5 2}$ & 0.641 & 0,785 & 0,902 & 1,185 & 1,79 \\
\hline
\end{tabular}

Specimen A-3

\begin{tabular}{|c|c|c|c|c|c|c|}
\hline \multirow{2}{*}{$S$} & \multirow{2}{*}{$\begin{array}{l}\text { Width } \\
(\mathrm{mm})\end{array}$} & \multicolumn{5}{|c|}{ WEB THICKNESS, $t_{w}(\mathrm{~mm})$} \\
\hline & & 3,9 & 5 & 6 & 7,6 & 10,5 \\
\hline N.A. & N.A. & N.A. & N.A. & N.A. & N.A. & N.A. \\
\hline N.A. & N.A. & N.A. & N.A. & N.A. & N.A. & N.A. \\
\hline $1,3 d_{o}$ & 94,5 & 0,498 & 0,656 & 0,763 & 1,036 & 1,367 \\
\hline $1,4 d_{o}$ & 126 & 0,566 & 0,632 & 0,732 & 0,925 & 1,221 \\
\hline $1,5 d_{o}$ & 157,5 & 0,606 & 0,76 & 0,808 & 1,072 & 1,421 \\
\hline $1,6 d_{o}$ & 189 & 0,675 & 0,705 & 0,822 & 1,099 & 1,482 \\
\hline $1,7 d_{o}$ & 220,5 & 0,512 & 0,755 & 0,854 & 1,173 & 1,661 \\
\hline $1,8 d_{o}$ & 252 & 0,642 & 0,764 & 0,921 & 1,186 & 1,803 \\
\hline
\end{tabular}

Specimen B-2
\begin{tabular}{|c|c|c|c|c|c|c|}
\hline \multirow{2}{*}{$\boldsymbol{S}$} & \multirow{2}{*}{$\begin{array}{c}\text { Width } \\
\end{array}$} & $(\boldsymbol{m m})$ & \multicolumn{5}{|c|}{ WEB THICKNESS, $\boldsymbol{t}_{\boldsymbol{w}}(\mathbf{m m})$} \\
\cline { 3 - 7 } & $\mathbf{3 , 9}$ & $\mathbf{5}$ & $\mathbf{6}$ & $\mathbf{7 , 6}$ & $\mathbf{1 0 , 5}$ \\
\hline $\mathbf{0 , 9 3 1 d}_{\boldsymbol{o}}$ & $\mathbf{3 1 . 5}$ & 0,105 & 0,166 & 0,198 & 0,285 & 0,321 \\
\hline $\mathbf{1 , 0 3 1 d}_{\boldsymbol{o}}$ & $\mathbf{6 3}$ & 0,177 & 0,293 & 0,347 & 0,422 & 0,524 \\
\hline $\mathbf{1 , 1 3 1 d}_{\boldsymbol{o}}$ & $\mathbf{9 4 , 5}$ & 0,236 & 0,361 & 0,461 & 0,562 & 0,702 \\
\hline $\mathbf{1 , 2 3 1 d _ { \boldsymbol { o } }}$ & $\mathbf{1 2 6}$ & 0,283 & 0,482 & 0,556 & 0,672 & 0,855 \\
\hline $\mathbf{1 , 3 3 1 d _ { \boldsymbol { o } }}$ & $\mathbf{1 5 7 , 5}$ & 0,279 & 0,549 & 0,604 & 0,824 & 1,018 \\
\hline $\mathbf{1 , 4 3 1 d _ { \boldsymbol { o } }}$ & $\mathbf{1 8 9}$ & 0,308 & 0,553 & 0,687 & 0,87 & 1,205 \\
\hline $\mathbf{1 , 5 3 1 d}_{\boldsymbol{o}}$ & $\mathbf{2 2 0 , 5}$ & 0,404 & 0,576 & 0,786 & 1,044 & 1,341 \\
\hline $\mathbf{1 , 6 3 1 d}_{\boldsymbol{o}}$ & $\mathbf{2 5 2}$ & 0,358 & 0,635 & 0,776 & 1,04 & 1,464 \\
\hline
\end{tabular}

Specimen B-3

\begin{tabular}{|c|c|c|c|c|c|c|}
\hline \multirow{2}{*}{$\boldsymbol{S}$} & \multirow{2}{*}{$\begin{array}{c}\text { Width } \\
\text { Sm }\end{array}$} & \multicolumn{5}{|c|}{ WEB THICKNESS, $\boldsymbol{t}_{\boldsymbol{w}}(\mathbf{m m})$} \\
\cline { 3 - 7 } & $\mathbf{3 , 9}$ & $\mathbf{5}$ & $\mathbf{6}$ & $\mathbf{7 , 6}$ & $\mathbf{1 0 , 5}$ \\
\hline $\mathbf{0 , 5 2 3 d _ { \boldsymbol { o } }}$ & $\mathbf{3 1 . 5}$ & 0,102 & 0,136 & 0,17 & 0,23 & 0,292 \\
\hline $\mathbf{0 , 6 2 3 d _ { \boldsymbol { o } }}$ & $\mathbf{6 3}$ & 0,17 & 0,257 & 0,322 & 0,447 & 0,503 \\
\hline $\mathbf{0 , 7 2 3 d _ { \boldsymbol { o } }}$ & $\mathbf{9 4 , 5}$ & 0,249 & 0,324 & 0,415 & 0,575 & 0,712 \\
\hline $\mathbf{0 , 8 2 3 d _ { \boldsymbol { o } }}$ & $\mathbf{1 2 6}$ & 0,293 & 0,43 & 0,509 & 0,653 & 0,845 \\
\hline $\mathbf{0 , 9 2 3 d _ { \boldsymbol { o } }}$ & $\mathbf{1 5 7 , 5}$ & 0,38 & 0,485 & 0,534 & 0,81 & 0,94 \\
\hline $\mathbf{1 , 0 2 3 d _ { \boldsymbol { o } }}$ & $\mathbf{1 8 9}$ & 0,412 & 0,527 & 0,562 & 0,79 & 1,053 \\
\hline $\mathbf{1 , 1 2 3 d _ { \boldsymbol { o } }}$ & $\mathbf{2 2 0 , 5}$ & 0,39 & 0,514 & 0,603 & 0,851 & 1,192 \\
\hline $\mathbf{1 , 2 2 3 d _ { \boldsymbol { o } }}$ & $\mathbf{2 5 2}$ & 0,459 & 0,55 & 0,735 & 1,063 & 1,435 \\
\hline
\end{tabular}

\begin{tabular}{|c|c|c|c|c|c|c|}
\hline \multirow{2}{*}{$S$} & \multirow{2}{*}{$\begin{array}{l}\text { Width } \\
(\mathrm{mm})\end{array}$} & \multicolumn{5}{|c|}{ WEB THICKNESS, $t_{w}(\mathrm{~mm})$} \\
\hline & & 3,9 & 5 & 6 & 7,6 & 10,5 \\
\hline $0,65 d_{o}$ & 31.5 & 0,139 & 0,176 & 0,233 & 0,337 & 0,383 \\
\hline $0,75 d_{o}$ & 63 & 0,211 & 0,338 & 0,414 & 0,52 & 0,669 \\
\hline $0,85 d_{o}$ & 94,5 & 0,277 & 0,467 & 0,524 & 0,652 & 0,882 \\
\hline $0,95 d_{o}$ & 126 & 0,357 & 0,54 & 0,628 & 0,806 & 1,01 \\
\hline $1,05 d_{o}$ & 157,5 & 0,409 & 0,57 & 0,676 & 0,849 & 1,095 \\
\hline $1,15 d_{o}$ & 189 & 0,43 & 0,611 & 0,754 & 0,907 & 1,214 \\
\hline $1,25 d_{o}$ & 220,5 & 0,408 & 0,635 & 0,755 & 0,946 & 1,398 \\
\hline $1,35 d_{o}$ & 252 & 0,537 & 0,653 & 0,786 & 0,997 & 1,599 \\
\hline
\end{tabular}

\subsection{Design model}

Compressive and tensile forces act across the web-post on opposite diagonals, as illustrated in Figure 6. Failure occurs when a local web buckle formed adjacent to the web opening as shown by the shaded areas. The compressive stress acting on the strut was calculated using the force in the upper tee-section or half the applied vertical shear force for a symmetrically placed opening.

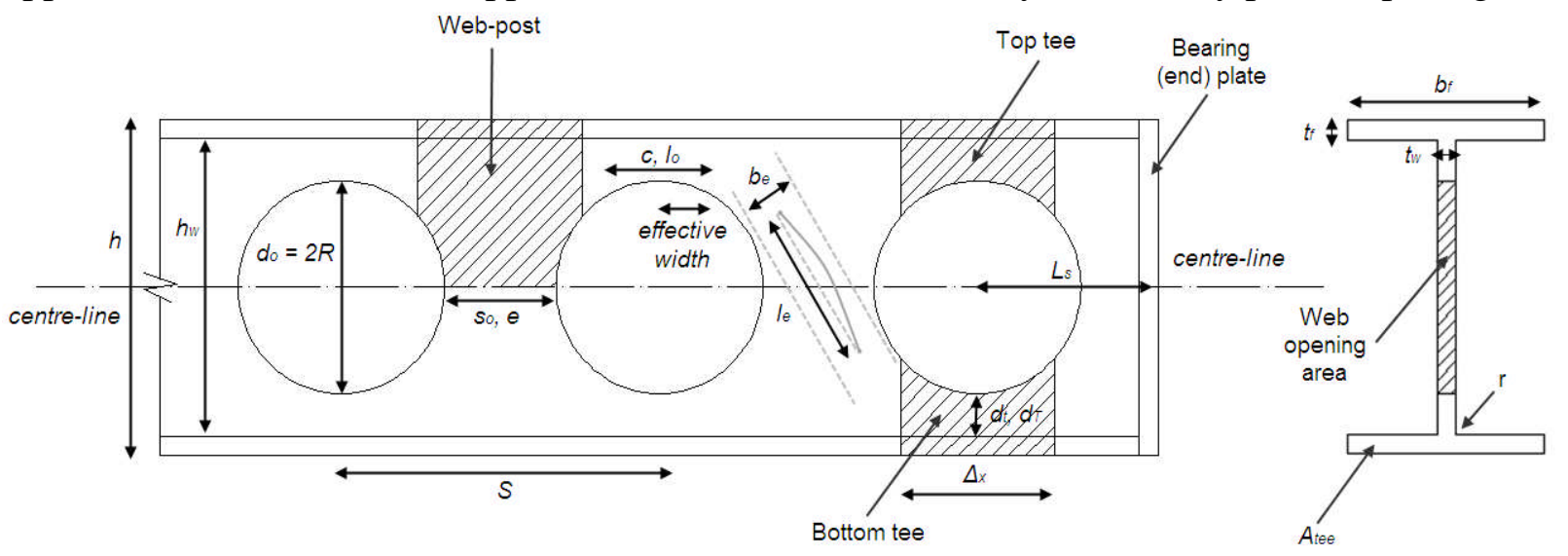

Fig. 6: Geometrical key parameters and strut model of web-post buckling 


\subsection{Results of the parametric FE study}

The vertical shear capacities obtained from the FE analyses of the web-posts are graphically represented in Figure 7. Improved design formulas have been developed for perforated sections with circular web openings (A1 \& B1) which cover the range of $1,1 \leq S / d_{o} \leq 1,8$. As a result of the non-linear FE parametric study on 225 models presented in Table 3, similar formulas have been proposed for perforated sections with the aforementioned novel web openings.
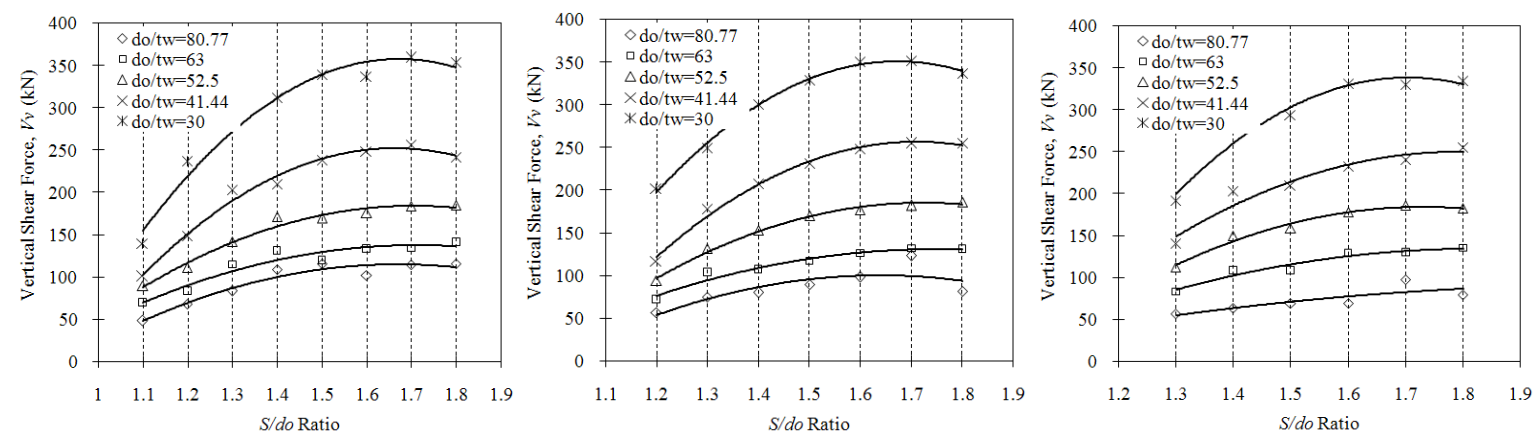

Fig. 7(a): Vertical shear resistance evaluated from FEA (Specimen A1/B1, A2 and A3)
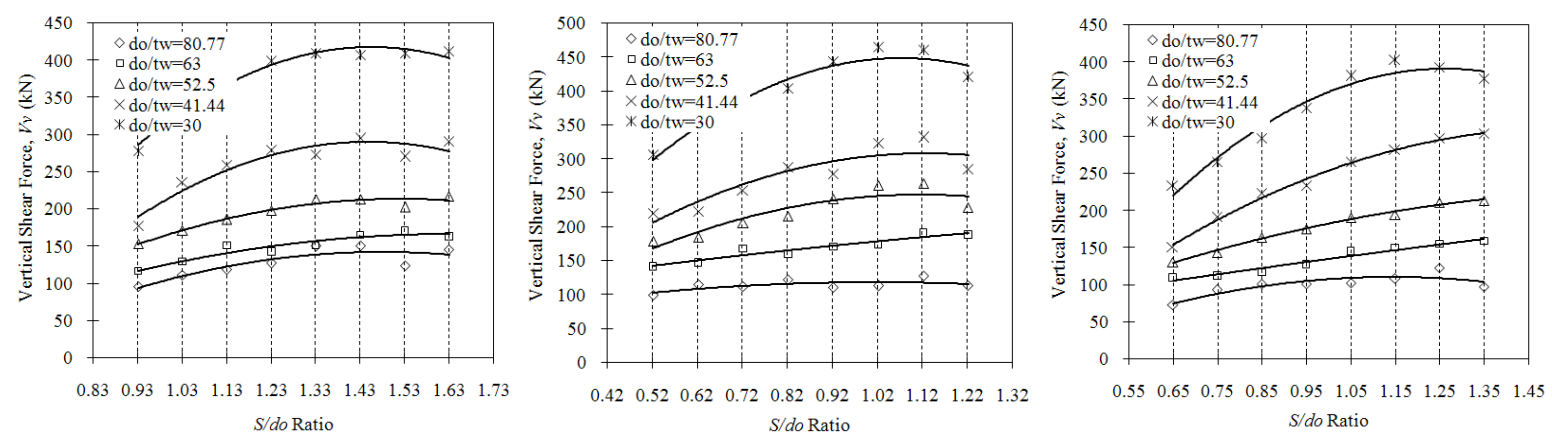

Fig. 7(b): Vertical shear resistance evaluated from FEA (Specimen B2, B3 and B4)

\subsection{Comparison of theoretical and FE results}

The strut is considered to act diagonally across the member as shown in Figure 6. The effective width, $b_{e}$, of the strut is always taken as half of the width of the web-post for use in determining the compressive stresses (Equation 1). The effective length, $l_{e}$, of the strut is calculated as the diagonal distance across the web-post using an effective length factor of 0,5 as assumed in the literature [6] for circular web openings (Equation 2). The slenderness, $\lambda$, of the web-post is then calculated as shown in Equation 3. This value of slenderness is used to obtain the compressive strength, $p_{c}$, from buckling curve 'c' of BS 5950-1 [7], which is appropriate for fabricated sections. The vertical shear resistance, $V_{v}$, due to web-post buckling is calculated as it is shown on Equation 4. Table 3 also represents the comparison of the vertical shear forces evaluated by the basic design model found in the literature and the FE model develop in this research study. There is conservatism up to $79 \%$ for narrow and thin web-posts, but the level of conservatism is reduced for wider web-posts with greater web thicknesses. The shaded areas indicate where the Vierendeel bending rather than the web-post buckling controls.

$$
b_{e}=0,5 * S_{o} \quad \text { (1) } \quad l_{e}=0,5\left(S_{o}^{2}+d_{o}^{2}\right)^{0,5} \quad \text { (2) } \quad \lambda=l_{e} *\left(12^{0,5}\right) / t_{w} \quad \text { (3) } \quad V_{v}=2 * b_{e} * p_{c} * t_{w}=p_{c} * S_{o} * t_{w}
$$

\subsection{Position of plastic hinges and effective widths of the web openings}

Table 4 illustrates the position of the plastic hinges in terms of an angle $\varphi$ and so the effective opening widths for circular and elliptically-based web opening shapes. The positions of plastic 
hinges are estimated from models with not too closely spaced web openings to avoid having transfer of stresses between the edges of two adjacent web openings.

Table 4: Summary of equivalent effective widths for novel web openings

\begin{tabular}{|c|c|c|c|c|c|c|}
\hline \multirow{2}{*}{ Specimen } & \multirow{2}{*}{$\begin{array}{c}\text { p range } \\
\text { (degrees) }\end{array}$} & \multicolumn{2}{|c|}{ Due to Vierendeel action } & \multicolumn{2}{|c|}{ Due to web-post buckl. action } & \multirow{2}{*}{$\begin{array}{l}\text { Max. used } \\
\varphi(\text { degrees })\end{array}$} \\
\hline & & $\varphi$ (degrees) & Eff. open. width & $\varphi($ degrees $)$ & Eff. open. width & \\
\hline$A 1 / 2 / 3 \& B 1$ & $20-29$ & 28 & $0,25 d_{o}$ & 28 & $0,25 d_{o}$ & 28 \\
\hline B2 & $13-22$ & 22 & $0,18 d_{o}$ & 17 & $0,14 d_{o}$ & 22 \\
\hline$B 3$ & $12-22$ & 12 & $0,1 d_{o}$ & $12-14$ & $0,1-0,13 d_{o}$ & 12 \\
\hline$B 4$ & $15-30$ & 21 & $0,18 d_{o}$ & $17-45$ & $0,15-0,28 d_{o}$ & 21 \\
\hline
\end{tabular}

$d_{0}$ : Web opening depth

\section{Conclusions}

The conclusions from the parametric FE work conducted on 225 models are:

- Some specimens are governed by Vierendeel bending capacity when the web thickness is between $7,6 \mathrm{~mm}<t_{w}<10,5 \mathrm{~mm}$ and the web-post width is between $63 \mathrm{~mm}<s_{o}<252 \mathrm{~mm}$. In general, when novel elliptically-based web openings are considered, the critical openings length is narrower and hence the Vierendeel capacity is high.

- From the Figure 7 it can be seen that in general the vertical shear capacities increase as the webpost width is increased, and conversely slightly decreased when they are subjected to high Vierendeel bending forces. However, when narrow elliptically-based web openings are considered, the capacity only gradually increases as Vierendeel bending is not critical.

- The existence of the fillets at the mid-height of the web opening with different radiuses such as Specimens A2 and A3, does not affect the vertical shear capacity of the web-posts. In fact, they behave similarly beyond a certain web-post width.

- The maximum shear stresses are lower in Specimens B3 and B4 for any web opening spacing and Specimen B2 when the web opening spacing is greater than $1,131 d_{o}$, due to better stress distribution.

- The maximum shear stresses move from the mid-height of the web-post towards the centroid of the axial forces and closer to the flanges, for relatively wide web opening spacing.

\section{References}

[1] Zaarour W., Redwood R., "Web buckling in thin webbed castellated beams", Journal of Structural Engineering, Vol.122, No.8, 1996, paper 11030.

[2] Chung K.F., Liu T.C.H., Ko A.C.H., "Steel beams with large web openings of various shapes and sizes: an empirical design method using a generalized moment-shear interaction", Journal of Constructional Steel Research, Vol. 59, 2003, pp. 117-1200.

[3] Tsavdaridis K.D., and D’Mello C., "Vierendeel Bending Study of Perforated Steel Beams with Various Novel Shapes of Web Openings, through Non-linear Finite Element Analyses", ASCE Journal of Structural Engineering, 2011. (DOI:10.1061/(ASCE)ST.1943-541X.0000562)

[4] Tsavdaridis K.D., and D'Mello C., "Web Buckling Study of the Behaviour and Strength of Perforated Steel Beams with Different Novel Web Opening Shapes", The Journal of Constructional Steel Research, Vol. 67, Issue 10, 2011, pp. 1605-1620.

[5] Tsavdaridis, K.D., "Structural Performance of Perforated Steel Beams with Novel Web Openings and with Partial Concrete Encasement", City University, London, 2010.

[6] Ward J.K., "Design of composite and non-composite cellular beams", The Steel Construction Institute, 1990, SCI P-100.

[7] British Standard Institution. BS5950-1: 2000, "Structural use of steelworks in building", BSI. 